UDC: 621.315 .592

\title{
Formation peculiarities of free-standing III-v single crystalline films prepared by solution method
}

\author{
Antoschenko V.S..$^{2 *}$, Migunova A.A. ${ }^{1}$, Francev Yu.V. ${ }^{2}$, Lavrischev O.A. ${ }^{1}$, Antochshenko Y.V. ${ }^{2}$ \\ ${ }^{\prime}$ Physico-Technical Faculty, al-Farabi Kazakh National University, Almaty, Kazakhstan \\ ${ }^{2}$ Scientific-Research Institute of Experimental and theoretical physics al-Farabi Kazakh National University, \\ Almaty, Kazakhstan
}

\begin{abstract}
In this paper, liquid phase epitaxy method used for the synthesis of free-standing single crystalline films of III$\mathrm{V}$ compounds by interaction of the quaternary Sn-Al-Ga-As liquid with binary solid GaAs substrate. It is shown that the possibility of the formation of free-standing single-crystalline films in such systems is determined by thermodynamic and kinetic conditions near liquid-solid interface at the growth temperature. On the basis of thermodynamic analysis and experimental study of similar multi-component systems were identified key crystallization criteria of these films. These criteria were used to predict the synthesis of free-standing binary semiconductor films on a distance from the initial semiconductor substrate in some systems.
\end{abstract}

Keywords: Free-standing film, Gallium Arsenide, Solution Growth, Phase Equilibrium, III-V Compounds. PACS: 68.35.Fx, 68.65.Ac

\section{Introduction}

Over the past decade, has developed several methods for producing thin films of single-crystal gallium arsenide allows you to reuse the same costly substrate. These include Peeled Film Technology (PFT) [1], Cleavage of Lateral Epitaxial Films for Transfer (CLEFT) [2], weight induced epitaxial liftoff (WI-ELO) [3]. However, currently the most widely used is the WI-ELO method. At its base, as in the PFT technique is preliminary formation of a sacrificial AlGaAs layer with Al concentration above $60 \%$ on the GaAs substrate and the subsequent growth of a desired film, or device structure. After growing a thin film structure, intermediate AlGaAs layer selectively removed in a hydrochloric acid or hydrofluoric acid solution, leading to the release of the grown structure from the substrate. The substrate is not destroyed, making it suitable for producing of a new cycle while the thin film structure can be bonded to a secondary substrate, and used independently.

In [4], an alternative method of synthesis of free-standing gallium arsenide films. It is based on the phenomenon of the abnormal growth of single crystalline films of certain A3B5 semiconductor compounds during crystallization from the tinaluminum melt, when an epitaxial film, as contrasted to conventional LPE, is formed not on the substrate but at a small distance from it in the volume of solvent. This paper presents an analysis of the conditions that lead to the synthesis of freestanding single crystalline films during the solution crystallization.

\section{Results and discussion}

Previously, it was found for GaAs substrates that separated film had a single crystalline structure with crystallographic orientation of the substrate and repeats its natural or artificially generated topography (fig.1).

Elemental analysis of the cross sections of the film / melt / substrate structure showed that the composition of the film and the substrate are identical (Figure 2a) except for a narrow area in the film from the substrate, wherein the composition is close to the AlAs (2b).

* Corresponding author: e-mail: solartechnology@mail.ru 

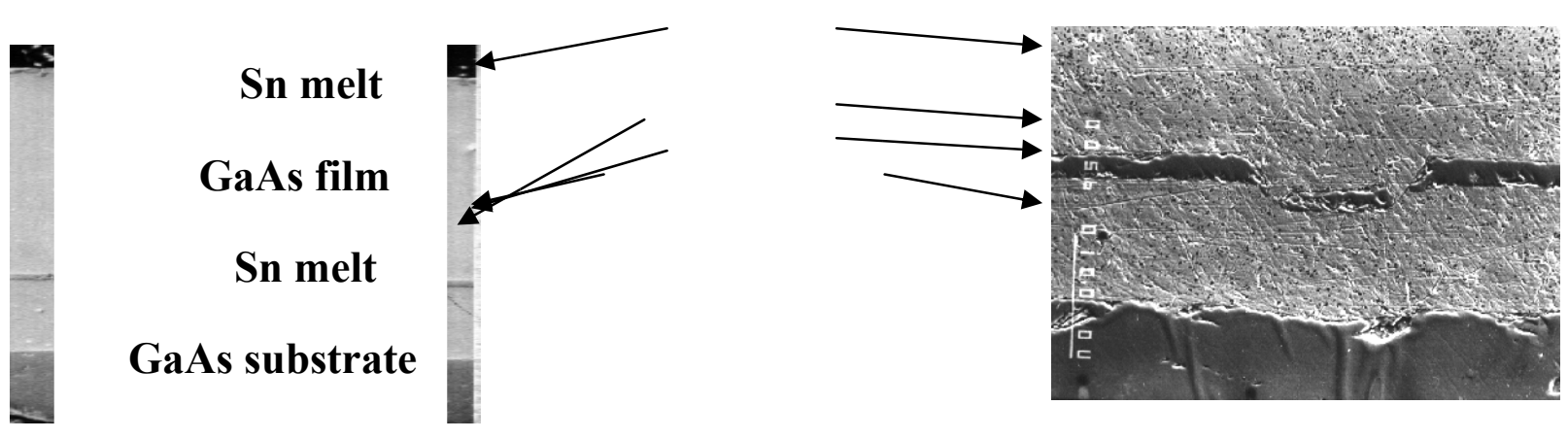

Figure 1 - Cross-section of structures, grown up at a distance from the substrate

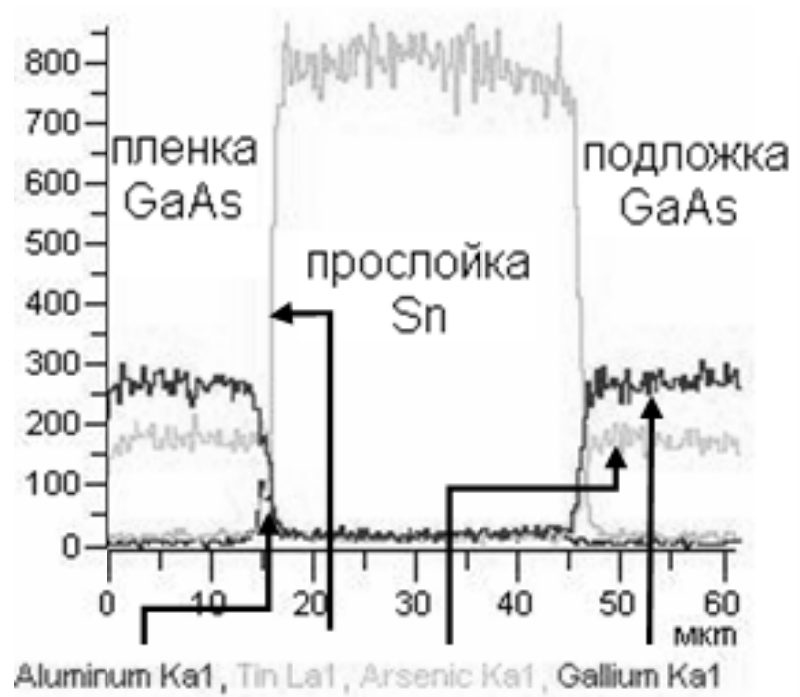

a

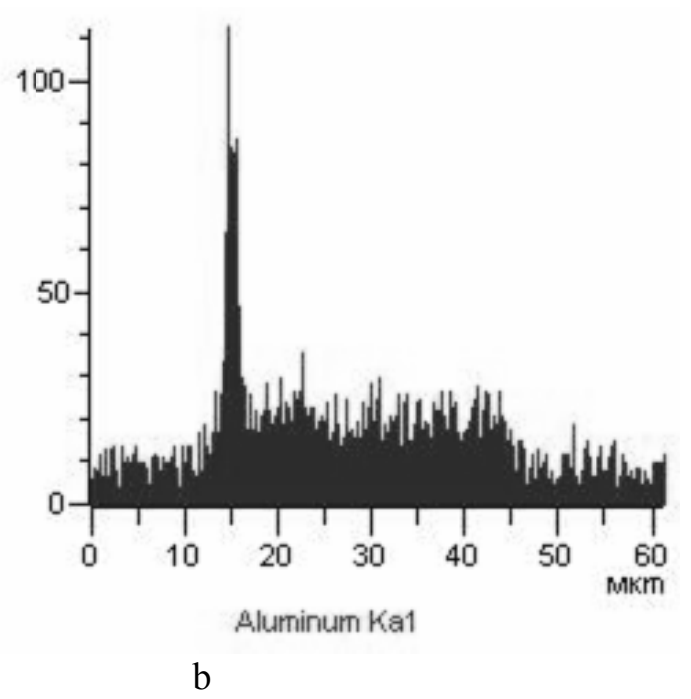

Figure 2 - Elements distribution in an abnormally grown structure

It was found that the initial stage of growth proceeds by the formation of thin aluminum arsenide layer on the substrate surface and simultaneous substrate dissolution under the layer through dislocattions. As a result, under certain process conditions in the volume of the solvent formed freely located AlAs single crystalline matrix substrate on which can be grown GaAs film or device structure. Electron microscopic examination of the AlAs matrix thickness shown magnitude of 20-80 nanometers, depend on the synthesis conditions (fig.3).

To understand the mechanism of separated films crystallization was carried out a study of phase equilibria in systems which exhibit abnormal growth of films: Sn-Ga-Al-As [4,5], Sn-Ga-Al-P [6], Sn-In -Ga-P [7] and the Bi-Ga-Al-As [8]. The typical form of the liquidus and solidus isotherms for these systems in the field of metal-rich solvent shown on fig. 4. As an example we choose the Sn$\mathrm{Ga}-\mathrm{Al}-\mathrm{As}$ system. The vertical line in the figure defines the narrow range of of Al concentrations, corresponding to the optimal mode of synthesis of autonomous films. This narrow concentration range and a small content of $\mathrm{Al}$ in the liquid phase needed to $\mathrm{AlGaAs}$ solid solution crystallization, as well as abnormally high values of the Al segregation coefficient in the field of $\mathrm{Sn}$ or $\mathrm{Bi}$-based systems, impose strict requirements for the implementation of the synthesis of free-standing films. This applies particularly to the steps of applying an Sn-Al melt unsaturated with arsenic on the GaAs substrate, when the interphase boundary is far from equilibrium. To obtain reproducible films arranged freely under these conditions were designed devices to stabilize the composition of non-equilibrium liquid phase during its application to the substrate. 


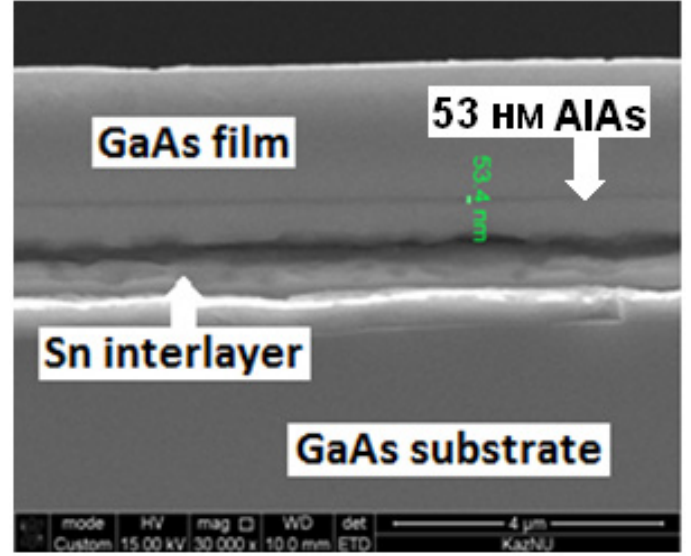

Figure 3 - Fragment of GaAs/AlAs/GaAs structure, synthesized in the system of Sn-Ga-Al-As

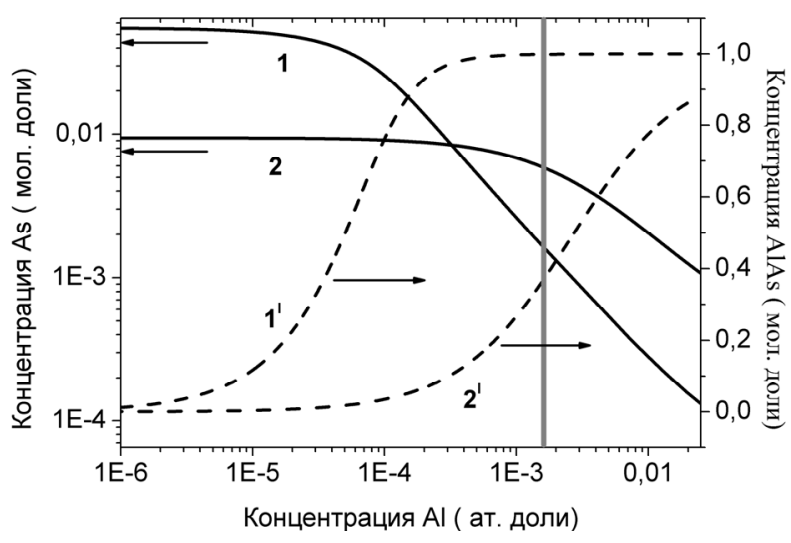

Figure 4 - GaAs solubility in molten $\mathrm{Sn}-\mathrm{Al}$ (1) and Ga$\mathrm{Al}(2)$ at $1000 \mathrm{~K}$ and a corresponding change in the composition of the AlGaAs solid solution (1', 2') depending on the $\mathrm{Al}$ concentration in the liquid phase

Studies have shown that the temperature dependence for optimum aluminum concentration in liquid $\left(\mathrm{C}_{\mathrm{Al}}\right)$ to grow perfect free-standing films using the Sn-Al-Ga-As system can be expressed (in atomic percent) as: $\mathrm{C}_{\mathrm{Al}}=3,3 \mathrm{E}-3[\exp (2160 /(\mathrm{Tm}-\mathrm{T})]$, where $\mathrm{Tm}$ is the substrate melting point,$- \mathrm{T}$ is a temperature at which the substrate contacted to the melt.

An important role at free-standing matrix films formation plays behavior of liquidus and solidus isotherms in quaternary systems based on inert solvents. Existence of the intersection point for the liquidus isotherms (1 and 2 in Figure 4), result in change of sign of As solubility: on it left the As solubility decrease with the increasing of Ga concentration in liquid but on it right As solubility increase with $\mathrm{Ga}$ concentration. In addition the solid phase composition around intersection point is near AlAs. This two factors determine the relaxation kinetics at liquid-solid interface when the dissolution of the substrate and the growth of new phase occur simultaneously. In accordance with the "growthdissolution" mechanism, after touch the substrate with a $\mathrm{Sn}-\mathrm{Al}$ melt at given temperature, in local areas will go substrate dissolution, whereas in the neighboring areas will form AlAs islands. Depending on the $\mathrm{Al}$ concentration at the interface will prevail one or other mechanism for determining the resulting process toward dissolution or growth. In the phase area of separated growth the greater part of the substrate surface covered with a AlAs layer, and a localized region of dissolution, remain a source of GaAs to saturate the liquid phase. Because of high lateral speed of substrate dissolution, the saturation of the liquid phase is due to substrate dissolution near AlAs film. Under certain conditions this process lead to complete separation of the single crystalline AlAs matrix and it "hovering" above the initial substrate in free-standing position. During the subsequent cooling procedure, on the matrix film can be grown GaAs-based device structure.

Numerous experiments have shown that the possibility of the synthesis and perfection of the thin film material is primarily determined by the thermodynamic parameters of binary semiconductors forming a ternary solid solution during the growth process. Table 1 summarizes some of the thermodynamic characteristics of experimentally investigated systems located in the descending order of separated films quality and the increasing degradation of the substrate. It includes the compound melting temperature $(\mathrm{Tm})$, the melting temperature difference between compounds forming a solid solution $\Delta \mathrm{Tm}$, the difference in their heats of formation $\Delta\left(-\Delta \mathrm{H}_{0,298}\right)$ and the heat of formation for highertemperature compound $-\Delta \mathrm{H}_{0,298}(\mathrm{a}$ - film, $\mathrm{b}$ - substrate). 
Table 1 - Some thermodynamic parameters of individual III-V semiconductor compounds

\begin{tabular}{|c|c|c|c|c|c|c|}
\hline \multicolumn{2}{|c|}{ System } & \multicolumn{2}{c|}{$\begin{array}{c}\text { Melting point } \\
\mathrm{T}_{\mathrm{m}, \mathrm{K}}\end{array}$} & $\begin{array}{c}\Delta \mathrm{T}_{\mathrm{m} .}, \\
\mathrm{K}\end{array}$ & $\begin{array}{c}\Delta\left(-\Delta \mathrm{H}_{298}\right) \\
\mathrm{kJ} / \mathrm{mole}\end{array}$ & $\begin{array}{c}-\Delta \mathrm{H}_{0,298} \\
\mathrm{~kJ} / \mathrm{mole}\end{array}$ \\
\hline $\mathrm{a}$ & $\mathrm{b}$ & $\mathrm{a}$ & $\mathrm{b}$ & & & $\mathrm{a}$ \\
\hline $\mathrm{AlP}$ & $\mathrm{GaP}$ & 2823 & 1738 & 1085 & 72,0 & 165,4 \\
\hline $\mathrm{AlAs}$ & $\mathrm{GaAs}$ & 2013 & 1511 & 502 & 45,4 & 116,4 \\
\hline $\mathrm{GaP}$ & $\mathrm{InP}$ & 1738 & 1343 & 395 & 4,7 & 93,4 \\
\hline $\mathrm{AlSb}$ & $\mathrm{GaSb}$ & 1323 & 985 & 338 & 5,0 & 49,2 \\
\hline
\end{tabular}

It is seen that the substrate has always a lower melting point than epitaxial matrix film growing on the substrate after contact with a liquid phase. Since the initial solid phase in these systems is a more high-temperature binary compound, the analysis based on the comparison of the properties of binary semiconductors is reasonable. References data and our own experiments show that separated growth is impossible in systems where the melting temperature of the substrate higher than the melting temperature of an initial solid phase. Such systems are, for example, In-Ga-As / GaAs, In-Ga-P / GaP et al. Reduction of difference in melting points of compounds forming system leads to a reduction in the quality of the free-standing film. This is due to a decrease in "protective" properties of initial epitaxial film insulated substrate from dissolution. Similarly the "quality" of separated growth decreases with difference decreasing between the heats of binary compounds formation. In a high-temperature system, the energy gain from the crystallization of a wide-gap semiconductor is much higher. Thus, we can conclude that separated growth should be expected in systems with large difference in melting points and the heat of formation of binary compounds, and substrate material should have a lower melting point.

Taking into account the last conclusion, we can assume probability of free-standimg growth in the systems: Al-In-As / InAs $(\Delta \mathrm{Tm}=803 \mathrm{~K}$, $\Delta(-\Delta \mathrm{N} 298)=58.6 \mathrm{~kJ} / \mathrm{mol})$, Ga-In-P $/$ InAs $(\Delta \mathrm{T} \mathrm{m}$ $=528 \mathrm{~K}, \Delta(-\Delta \mathrm{N} 298)=35.6 \mathrm{~kJ} / \mathrm{mol})$, Ga-As- $\mathrm{N} /$ GaAs $(\Delta \mathrm{Tm}=459 \mathrm{~K}, \Delta(-\Delta \mathrm{N} 298)=39,9 \mathrm{kDzh} /$ mol $)$, Al-In- P / InP $(\Delta \mathrm{Tm}=1480 \mathrm{~K}, \Delta(-\Delta \mathrm{N} 298)=$ $76.7 \mathrm{~kJ} / \mathrm{mol}$ ), and others. It should however be borne in mind the need to close lattice parameters (see. Table 2), and the identity of the crystalline type of the materials, and certain other requirements to solid solutions LPE, for example, it need a sufficiently high solubility of the substrate's material at growth temperature.

Table 2 - The influence of the mismatch of the lattice parameters of semiconductor compounds on the growth characteristics of free-standing films

\begin{tabular}{|c|c|l|}
\hline System & $\Delta$ a, $\%$ & \multicolumn{1}{c|}{ Growth characteristics } \\
\hline AlP-GaP & $<0,01$ & High film perfection, planar dissolution of GaP substrate (less than 2 um) \\
\hline AlAs-GaAs & 0,14 & High film perfection, planar dissolution of GaAs substrate (less than 5 um) \\
\hline AlSb-GaSb & 0,65 & Rough relief, deep, non uniform GaSb subsnrane dissolution (50-100 um), solvent inclusion \\
\hline GaP-InP & 7,3 & $\begin{array}{l}\text { Good film quality up to 2 um thickness. Increase in film thickness leads to island growth, weak } \\
\text { planar InP substrate dissolution }\end{array}$ \\
\hline
\end{tabular}

Table 2 shows that the quality of separated films falls, and the degradation degree of the substrate increases with the mismatch of the lattice parameters for the first three systems. However, in the GaP-InP, with maximum lattice mismatch at crystallization temperature good quality films are formed in a narrow range of thicknesses up to 2 um with a slight dissolution of the substrate. In the latter system, a strong lattice mismatch effects only when the film thickness is greater than the critical value. In this case, the elastic stresses generated in the growth process, increasing the interfacial energy at the heterointerface. Similarly, in the AlSb$\mathrm{GaSb}$ system island growth was observed, when the composition of the AlGaSb solid solution differs from the initial solid phase composition. Thus, the lattice mismatch of binary semiconductors forming a solid solution mainly affects the crystallization of the film when the process of matrix film separation and substrate dissolution has been completed and the subsequent growth is situated on the single crystalline matrix film free-standing in the volume of melt. 


\section{Conclusions}

Behavior of liquidus and solidus isotherms in quaternary systems based on inert solvents plays an important role at free-standing matrix films formation.

Separated growth is appeared in systems with large difference in melting points and heat of formation of binary compounds, and substrate material should have a lower melting point.

The quality of separated films falls, and the degradation degree of the substrate increases with mismatch in lattice parameters of the binary semiconductors.
Lattice mismatch of binary semiconductors forming a solid solution mainly affects after matrix film separation process and lead to growing film elastic deformation.

The studies have shown the promise of this method for making thin-film synthesis of functional structures for various purposes.

\section{Acknowledgment}

The work was supported by Ministry of Education and Science of RK (grants No. 1088/GF1/2014)

\section{References}

Konagai M., Sugimoto M., Takahashi K. High efficiency $\mathrm{GaAs}$ thin film solar cells by peeled film technology // J. Cryst. Growth. - 1978. - Vol.45. P. 277

McClelland R. W., Bozler C. O., Fan J. C. C. A technique for producing epitaxial films on reusable substrate // Applied Physics Letters. - 1980. - Vol. 37, N 6. - P. 560-562

Voncken M.A.J., Schermer J.J., Maduro G., Bauhuis G.J., Mulder P., Larsen P.K. Influence of radius of curvature on the lateral etch rate of the weight

induced epitaxial lift-off process // Mater. Sci. Eng. B. -2002 . - Vol.95. - P.242-248

V.S.Antoschenko, T.I.Taurbaev, Anomalnyi rost poluprovodnikovih plenok pri jidkostnoy epitaxii//
Electronnaja technika (6), Materialy, V. 2(201) (1985) 54-58.

V.S.Antoschenko, T.I.Taurbaev, Otdeliaemiy post sovershennih monokristallicheskih plenok v sisteme Sn-Ga-Al-As // Pisma v ZhTF . - 1990. - V.16, Iss.12. - P.1-5

V.S.Antoschenko, T.I.Taurbaev, J.Crystal Properties and Preparation, Vol.32-34 (1991)594

V.S.Antoschenko, T.I.Taurbaev, E.V.Skirnevskaya, 25th Conference on the Physics and Chemistry of Semiconductor Interfaces (PCSI-25), Abstr., (1998) P.89

V.S.Antoschenko, E.V. Skirnevskaya, T.I.Taurbaev, Bulletin KSNU, Natural science series, the first issue, (1997) P.83 